\title{
Management of allergic rhinitis in UK primary care: baseline audit
}

\author{
Dermot Ryan ${ }^{a, *}$, John Grant-Casey ${ }^{b}$, Glenis Scadding ${ }^{c}$, \\ Scott Pereira ${ }^{c}$, Hilary Pinnock ${ }^{d}$, Aziz Sheikh ${ }^{d}$
}

a Department of General Practice and Primary Care, University of Aberdeen, Westburn Road, Aberdeen AB25 2AY, UK

${ }^{b}$ Royal College of Pathologists, 2 Carlton House Terrace, London SW1Y 5AF, UK

c Royal National Throat, Nose and Ear Hospital, Grays Inn Road, London WC1X 8DA, UK

${ }^{\mathrm{d}}$ Division of Community Health Sciences: GP Section, University of Edilaurgh, UK

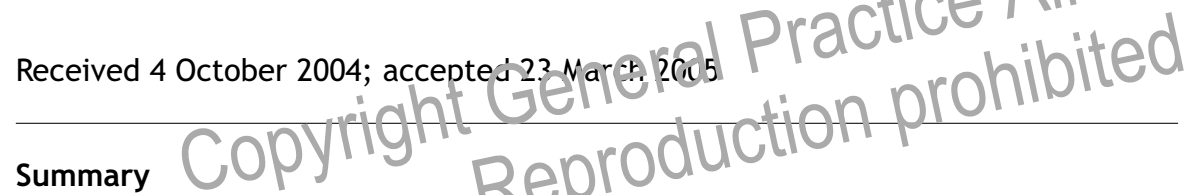

Background: Evidence suggests that the UK primary care management of people with allergic rhinitis is sub-optimal. Common deficiencies are thought to include under-diagnosis, mis-diagnosis and sub-optimal treatment.

Objectives: We sought to assess GPs' understanding and perspectives on key issues in the management of allergic rhinitis, comparing these with recommendations contained in the Consensus statement on the treatment of allergic rhinitis.

Methods: Sampling frame of $210 \mathrm{GPs}$ with a self-declared interest in the management of allergic and respiratory disorders from $70 \mathrm{GP}$ practices in the UK. Semi-structured interviews were used to assess GPs' knowledge and views on clinical practice. Trained personnel conducted all interviews. Interviews were taped and transcribed; each transcript was scrutinised to see if GP knowledge and practice was consistent with the standards set.

Standards and criteria: We used the most recent Consensus statement on the treatment of allergic rhinitis as our standard, aiming to assess quality of care in four main domains: identification of symptoms; collection of information to support a clinical diagnosis; examination and investigations performed to support the clinical diagnosis; treating and managing the condition.

\footnotetext{
* Corresponding author. Tel.: +44 1509 239166; fax: +44 1509239649.

E-mail address: dermotryan@doctors.org.uk (D. Ryan).
} 
Results: We successfully interviewed $90 \%(n=188)$ of GPs. Only $14 \%(n=26)$ of GPs satisfied all the criteria set for Standard 1 (identification of symptoms); $23 \%(n=43)$ satisfied criteria for Standard 2 (collection of information to support a clinical diagnosis); $0 \%(n=0)$ satisfied criteria for Standard 3 (examination and investigations performed to support the clinical diagnosis); and $0.6 \%(n=1)$ satisfied criteria set for Standard 4 (adequate treatment issued).

Conclusions: This national baseline audit of GPs with a self-declared interest in allergic and respiratory disorders reveals considerable scope for improvement in GP awareness and management of allergic rhinitis.

(C) 2005 General Practice Airways Group. Published by Elsevier Ltd. All rights reserved.

\section{Introduction}

Allergic rhinitis is the commonest chronic disease in the UK population, with an estimated prevalence of $20 \%$ [1]. In keeping with many other allergic disorders, disease prevalence is rising in the Western world, for reasons that are at present poorly understood [2-4]. If poorly controlled, allergic rhinitis is known to result in significant disease morbidity; furthermore, inadequately treated disease may be responsible for increased morbidity from asthma [5-7].

The overwhelming majority of cases of persistent and intermittent allergic rhinitis are managed almost exclusively within primary health care? the UK. Differing models of cared diveivocur in other

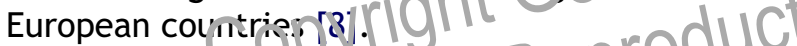

To investigate concerns that sut. Oot trnal cisease management might be contribucing to potentially preventable morbidity, we conducted a national baseline audit of general practitioners (GPs) with a self-declared interest in the management of allergic disease, assessing their understanding of and clinical practice within key areas in the management of allergic rhinitis, comparing this to recommendations contained in the Consensus statement on the treatment of allergic rhinitis [9].

This study, the first of its kind, provides a snapshot of GPs' perceptions of how they provide care to rhinitis sufferers.

\section{Methods}

Seventy UK GP practices with a self-declared specialist interest in the management of allergic and respiratory disorders listed in the 1999 issue of Guidelines were identified [10]. Three GPs from each practice were invited to participate in the baseline audit, giving a potential sample of $210 \mathrm{GPs}$.

Trained audit facilitators conducted face-to-face semi-structured interviews, during which enquiry was made about the GP's knowledge of key issues and their clinical management of allergic rhinitis through discussion of typical case scenarios. Interviews were taped and transcribed, and content analysis was performed by the audit co-ordinator.

Each interview transcript was scrutinised and compared against a pre-defined checklist to see if the GP demonstrated knowledge or practice consistent with these evidence-linked standards. These standards were derived from the Consensus Statement on the treatment of allergic rhinitis [9]. Four standards were derived that were measured by 21 criteria. These standards retated :0 four broad areas in the marlagenent of allergic rhinitis (see Tâble (1, Gr details):

- Identificatior) df cymptoms (4 criteria)

C(1).ection of information to support a clinical diagnosis (4 criteria)

- Examining and testing to support the clinical diagnosis (6 criteria)

- Treating and managing the disease (7 criteria).

\section{Results}

We successfully established contact and conducted interviews with $90 \%$ of the GPs invited to participate $(n=188)$.

Table 2 details the results of the overall level of attainment with respect to each of the four standards, whilst Fig. 1 illustrates graphically the level of attainment for each of the 21 individual criteria. We found a high level of attainment for criterion 3 (mention of runny nose), 5 (personal history of allergy), 6 (family history of allergy), 12 (examination of the nose), 18 (use of antihistamines) and 19 (use of nasal corticosteroids). This was contrasted by very low levels of attainment in relation to criterion 10 (investigation of skin symptoms), 11 (investigation to eliminate pollen related allergies), 13 (conducting skin prick testing), 14 (conducting allergy specific blood tests), 15 (advising allergen avoidance), 17 
Table 1 Allergic rhinitis standards and criteria.

Standard 1: GP can accurately describe the symptoms of allergic rhinitis as measured by the following criteria:

1. Mentions nasal itching or similar.

2. Mentions sneezing.

3. Mentions watery rhinorrhea or runny nose.

4. Mentions nasal obstruction or blocked nose.

Standard 2: GP takes an adequate history.

5. Asks about personal or family history of allergies.

6. Takes a personal and general family history.

7. Asks about recent symptoms experienced.

8. Asks about any treatment the patient has already received.

Standard 3: GP undertakes adequate examination and investigation of the suspected allergic rhinitis as measured by.

9. Investigates the patient to eliminate any lower respiratory tract disease.

10. Investigates to eliminate skin symptoms.

11. Investigates to eliminate pollen-related allergies.

12. Physically examines the patient's nose.

13. Conducts skin prick testing.

14. Performs blood tests for allergy-specific lgE.

Standard 4: GP operates an adequate therapeutic regime, measured by some, but not necessarily all, of the following criteria.

15. Control the symptoms by prevention of contact with the substance causing the allergy.

16. Identify and advise avoidance of the allergen.

17. Control the patient's environment so the allergen can be removed.

18. If the patient has mild symptoms of seasonal allergic rhinitis (SAR) treat the sym!conis with antihistamines if the hay fever season has started, or with crom c nes i Nit ha: not.

19. If the patient has moderate or uncontrolled $m$ ild y mpicms of seasonal ailergic rhinitis, treat with a topical nasal steroid If eve symirtom s are not controlled by t: Hurther treat with a topical ocular antihistainine e cionione.

20. If the patient has evere or uncontrolled roderales mptoms, use a combination of nasal steroids and/or top cal antinistam ine a cil'a fijus úrug and dose to control symptoms.

21. If symptoms remain uncontrulied, add oral or topical nasal decongestants, ipratropium bromide for watery rhinorrhea, analgesics for headache, or a short course of oral steroids.

(control of patient's environment) and 21 (other pharmacological interventions).

Many GPs met the criteria for identification of symptoms and family history, and most agreed that they would undertake a simple examination of the nose. They were, however, relatively unlikely to suggest any investigations. They were likely to recommend the use of antihistamines and nasal steroids, but unlikely to discuss allergen avoidance.

\section{Discussion}

This study, the first of its kind, provides a snapshot of the provision of care to patients suffering from allergic rhinitis in the UK, and reveals considerable potential deficiencies in standards of care. Given that interviewees' standards were subjective opinions of their own performance and were not subject to objective audit of clinical practice, these findings may present an over-optimistic view

Table 2 Number of GPs meeting standards $(n=188)$.

\begin{tabular}{llc}
\hline & GPs meeting standard $(n)$ & \% of total GPs \\
\hline Standard 1: Identification of symptoms & 26 & 13.8 \\
Standard 2: Collection of information to support a clinical diagnosis & 43 & 22.9 \\
Standard 3: Examining and testing to support the clinical diagnosis & 0 & 0 \\
Standard 4: Treating and managing the disease & 1 & 0.6 \\
\hline
\end{tabular}




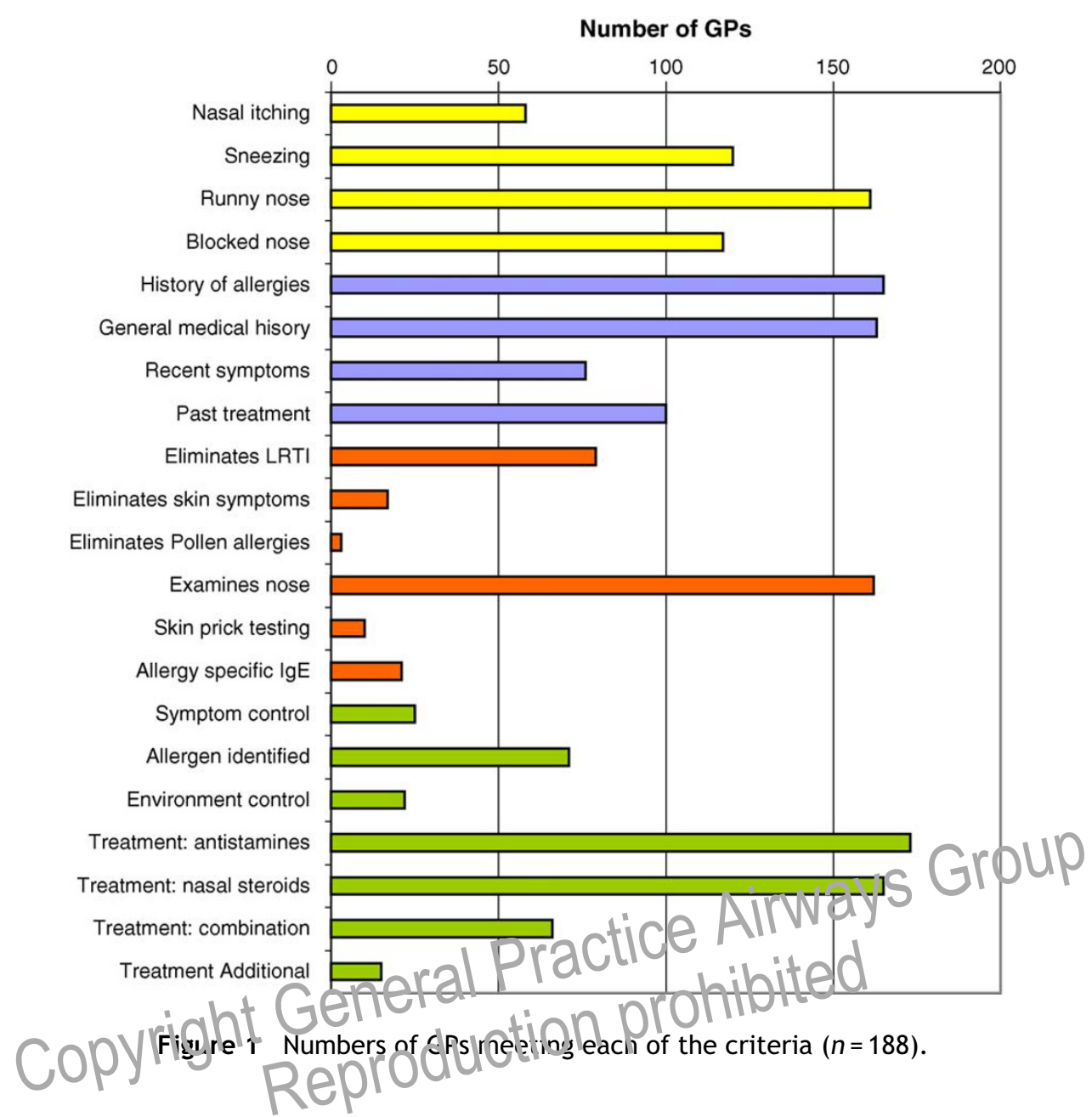

of the situation. The paucity of specialist allergy care provision has been highlighted recently, and suggests that, for the foreseeable future at least, most patients with allergic rhinitis in the UK will continue to be managed in primary care [11].

\section{Potential limitations}

Our sampling frame comprised GPs with a selfprofessed interest in the management of allergic disorders, so it is likely that we are underestimating the actual deficiencies in standards of care nationally.

However, it may be argued that these findings reflect inappropriateness of the guidelines used as our study standard for primary care use. At the time of the audit the only other guidelines available for any practitioner in the UK were the $\mathrm{BASCl}$ Rhinitis guidelines [12]. We do not possess evidence of the impact of these guidelines on the primary care physician but suspect that there was little awareness of them. Some support for this argument comes from the observation that these guidelines were developed by secondary and tertiary care practitioners who, by definition, tend to deal with more complex and severe cases and therefore need to adopt a more in-depth approach to assessment and management than is routinely needed in primary care [13]. The Consensus Statement on the treatment of allergic rhinitis [9] represents the gold standard in rhinitis management and may be more applicable to the patient whose symptoms cannot be remedied by relatively simple interventions. They do not contain specific recommendations for onward referral to a specialist, suggesting that the guideline was not intended as a tool for primary care. Furthermore, the leading authors of the guidelines practice in continental Europe and therefore the guidelines may well be better suited to health care systems which have superior provision of allergy services when compared to the UK.

Notwithstanding these possible explanatory factors, one would have expected a higher proportion of GPs to have met the criteria for standards 1 and 2. Although this study shows that only $41 \%$ of GPs routinely enquired about all four key symptoms, it was clear from the majority 
of interview transcripts that the GP expected a description of symptoms to form the basis for the rest of the consultation.

Another limitation of our questionnaire was in omitting to enquire whether or not interviewees posed questions pertaining to the effects of the disease on patients' quality of life, whether they asked any questions about what treatments had been purchased over the counter, and whether they asked for a demonstration of nasal inhaler technique, although there was no prompt in the guidelines to ask these important questions.

\section{Contextualising key findings}

It is only recently that attention has been drawn to the intimate link between upper and lower airway allergic disease, and many practitioners recognised the importance of this potential association [7]. The other deficiencies of care in standard 3 (examining and testing to support diagnosis) accurately reflect practice in UK general practice, and access to and use of investigations. The interview transcripts reveal many reasons for this: lack of time; lack of knowing what to look for; lack of knowledge on how to interpret results; lack of belief hat: it is necessary to undertake sucin in estigations, particularly blood testin? ic specific lgE (testing? for antibocies (to a barticular álersen); and, most strikingly, a reluctance to carry out skin-prick testing in the surgery.

Data relating to Standard 4 (treating and managing disease) are somewhat more difficult to interpret in that many of the set criteria have large areas of overlap which confounds analysis. Interview transcripts reveal the philosophy behind the GPs' actions or apparent lack of them. Thus many GPs do not believe it possible to identify, let alone avoid, the offending allergen or allergens, as there is a lack of evidence to support the recommendations made in the guidelines [14].

\section{Conclusions}

This baseline audit has uncovered areas of GP knowledge and practice that are at considerable variance with established evidence-linked guidelines for the management of allergic rhinitis. Whilst there are areas of knowledge and practice which achieved better scores in the audit than others, it is significant that no GP met all standards or criteria, and that less than half of our sample of GPs with a self-professed interest in the management of allergic conditions satisfied 12 out of the 21 criteria. We suggest that an educational intervention for GPs on all aspects of management of allergic rhinitis is now developed and evaluated. We further suggest that representatives of primary care are involved in the development of subsequent guidelines to ensure their relevance to that environment.

Source of Funding: Schwarz Pharma Limited

\section{Statement of existing or potential conflicts of interest:}

Dermot Ryan has been sponsored to attend major symposia by, received consultancy fees and speaker fees from, and arranged educational activities for, $3 \mathrm{M}$ Pharmaceuticals, Astra Zeneca, GlaxoSmithKline, Schering-Plough, MSD and Novartis Pharma.

John Grant-Casey: The audit was conducted using funds provided as an unconditional educational grant from Schwarz Pharma, who also sponsored John Grant-C.(S)=V's attendance at three confereplees un make presentations on the âuritif fincings.

Glenis Stadaing. Enas lectured for: Schering Plough, M.SD) CSK, Aventis, makers of mizolastine, ALK, Almirall. and has undertaken research for- GSK, ALK, UCB, Schering Plough. Glenis has also undertaken advisory panel/consultancy work for: GSK, Schering Plough, UCB, Aventis, MSD, Pfizer.

Scott Pereira: None declared

Hilary Pinnock: None declared

Aziz Sheikh: has received reimbursement for lectures and meetings from Schering-Plough Ltd., UCB Pharma, Aventis, Pfizer Ltd., GlaxoSmithKline.

\section{Acknowledgements}

The authors would like to thank Schwarz Pharma Ltd for their financial support.

\section{References}

[1] Austin JB, Kaur B, Anderson HR, et al. Hay fever, eczema, and wheeze: a nationwide UK study. Arch Dis Child 1999;81:225-30.

[2] Fleming DM, Crombie DL. Prevalence of asthma and hay fever in England and Wales. BMJ 1987;294:279-83. 
[3] Durham SR. Summer hay fever. In: Durham SR, editor. ABC of allergies. London: BMJ Books; 1998. p. 16-8.

[4] Blaiss MS. Quality of life in allergic rhinitis. Ann Aller Asthma Immunol 1999;83:449-54.

[5] Bousquet J, Bullinger M, Fayol C, et al. J Allergy Clin Immunol 1994;94:182-8. Assessment of the quality of life in patients with perennial allergic rhinitis with the French version of the sF-36 health status questionnaire.

[6] Sheikh A. Asthma and coexistent disease. Asthma Gen Pract 1998;6:17-8.

[7] ARIA guidelines Bousquet J, Van-Cauwenberge P, Khaltaev $\mathrm{N}$ and the ARIA group. Allergic rhinitis and its impact on asthma. J Allergy Clin Immunol 2001;108:S147333.

[8] European Allergy white Paper. UCB institute of Allergy 1997. Brussels.
[9] van Cauwenberge P, Bachert C, Passalacqua $G$, et al. Consensus statement on the treatment of allergic rhinitis. European Academy of Allergology and Clinical Immunology. Allergy 2000;55:116-34.

[10] Anon. Guidelines. Medendum Publications (Available from: http://www.eguidelines.co.uk/).

[11] Holgate S.H., editor. Allergy: the unmet need. A blueprint for better patient care. London: Royal College of Physicians; 2003.

[12] Rhinitis Management Guidelines (3rd edition). British Society for Allery and Clinical immunology Published by Martin Dunitz; 2000.

[13] Fraser RC. Clinical method. In: A general practice approach. Oxford: Butterworth; 1987.

[14] Sheikh A, Hurwitz B. House dust mite avoidance measures for perennial allergic rhinitis: a systematic review of efficacy. BJGP 2003;53:318-22.

Available online at www.sciencedirect.com

science@direct.

Available online at http://www.thepcrj.com

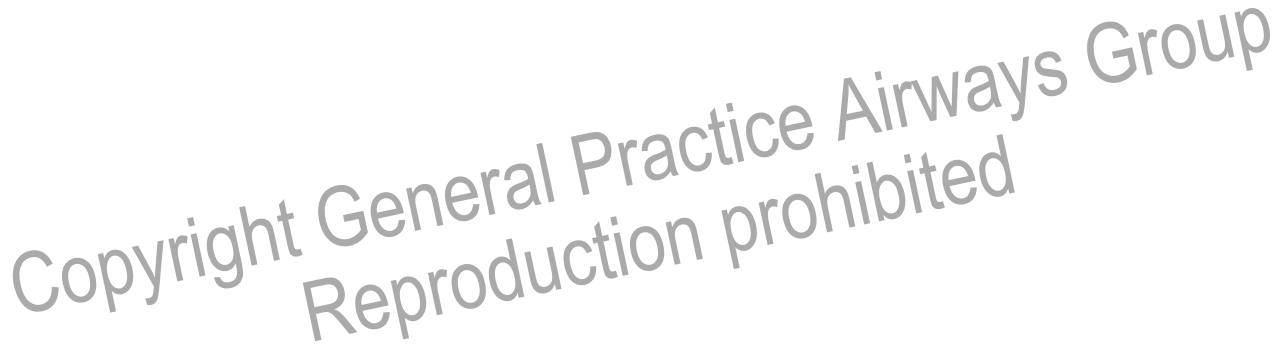

